\title{
ASPECTOS METODOLÓGICOS DE UMA CAMPANHA DE VACINAÇÃO
}

\author{
Iracy Silva Costa* \\ Zeile Novais Dias * \\ Maura M. ${ }^{a}$ Guimarães de Almeida * * \\ I - INTRODUÇÃO
}

O presente esturlo contém o relato de uma experiência da qual participaram professores dos Departamentos III e V, respectivamente, Enfermagem de Saúde Pública da Escola de Enfermagem e Saúde Coletiva da Faculdade de Medicina da Universidade Federal da Bahia, quando da realização de uma campanha visando ao combate a um surto de poliomielite, numa área urbana de Salvador-Bahia, no primeiro semestre de 1971.

Nordeste de Amaralina, área onde foi realizada a experiência, está localizada no subdistrito de Amaralina, Bairro de Salvador, tem uma população de aproximadamente 49.000 habitantes (3), com perspectiva de aumento desordenado devido ao crescente incremento populacional que ali se observa.

Com uma população de baixo nível sócio-econômico e cultural, além de outras características desfavoráveis como sejam: a topografia bastante acidentada, falta de demarcação de ruas, deficiência de saneamento básico, serviços assistenciais precários, principalmente cm termos da demanda, o Nordeste de Amaralina tem sido alvo das atenções da Universidade Federal da Bahia que ali desenvolve, há dois anos, um plano experimental de Desenvolvimento Comunitário, ein convênio com a Secretaria de Saúde Pública do Estado. E este um dos programas de extensão que a Universidade oferece, atendendo a um dos objetivos da reforma, o de integrar-se à comunidade, realizando o estudo sistemático de seus problemas e a formação de quadros científicos e técnicos ao nível de suas necessidades.

(*) Professor-Adjunto da Escola de Enfermagem da Univ. Federal da Bahia.

$\left({ }^{\star \star}\right)$ Professor-Assistente da Escola de Enfermagem da Univ. Federal da Bahia. 
Reconhece-se que na problemática de saúde do País ainda ocupam as doenças transmissíveis e evitáreis lugar de destaque, apesar do progresso científico e da melhoria dos recursos assistenciais.

Esta é uma realidade encontrada no Nordeste de Amaralina, através de dados resultantes de levantamentos ali realizados, que apontam as doenças transmissíveis como responsáveis por $40,0 \%$ do total de óbitos e por $55,9 \%$ do absenteísmo escolar (4).

Confirmando esta assertiva, em março de 1971, foram notificados à Unidade Sanitária da área casos de poliomielite da forma paralítica, envolvendo crianças com menos de onze meses a dois anos de idlade. Nesta mesma ocasião o Estado da Bahia apresentava um número elevado de casos de poliomielite, sugerindo um possível surto epidêmico. Este quadro impôs a necessidade de vacinação em massa, que foi programada com os seguintes objetivos:

- prevenir, através da vacinação do grupo etário de dois meses a três anos, a disseminação do surto de poliomielite no Nordestc de Amaralina;

- oferecer oportunidade de aprendizado aos estudantes de Enfermagem e Medicina no planejamento, execução e avaliação de uma campanha de vacinação.

\section{II - NETODOLOGIA}

Considerando a Educação Sanitária, cada vez mais reconhecida como instrumento essencial para colaborar na solução dos problemas de saúde, optamos pela realização de uma campanha por ser um mélodo educativo de motivação de massa, que estimula a comunidade no sentido da sua participação ativa como chave para o êxito dos programas de Saúde Pública.

Assim, estabelecida a conveniência do método de Campanha, adaptou-se às condições sócio-econômicas culturais e topográficas locais e, com base nesses fundamentos, traçou- se o plano em cinco etapas.

\section{1 - Responsabilidade da Campanha}

A responsabilidarle coube à Secretaria de Saúde Pública e à Universidade Federal da Bahia que, num exemplo de integração interinstitucional, vêm demonstrando a consciência da necessidade de participarem de forma cooperativa na análise, reflexão e solução dos problemas comuns. 
Apesar de terem ambas as Instituições competências definidas no plano de Desenvolvimento Comunitário implantado na área, elas se harmonizam no sentido da percepção das necessidades da comunidade, assim como da utilização mais produtiva dos recursos humanos e materiais disponíveis.

\section{2 - Formação do Grupo de Trabalho}

Delineada a responsabilidade sobre a Campanha, formou-se o grupo de trabalho encarregado do planejamento, execução e avaliação da mesma, subordinado a uma coordenação responsável por toda a sua dinâmica.

Integraram esse grupo a equipe técnica atuante no Nordeste de Amaralina, além de estudantes de enfermagem e medicina, professores primários, alunos da quinta série fundamental e líderes da comunidade.

A equipe técnica reuniu oito membros, sendo três médicos (professores do Departamento de Saúde Coletiva da Faculdade de Medicina) e cinco enfermeiras (quatro professoras do Departamento (le Enfermagem de Saúde Pública da Escola de Enfermagem e uma enfermeira da Unidade Sanitária da área). Esta equipe constituiu o núcleo do grupo de trabalho, por integrar profissionais da saúde que, por suas características, seriam os elementos mais interessados no projeto, consideradas, portanto, como pessoas-chave. Todavia, outros elementos da comunidade foram selecionados entre aqueles que participaram, direta ou indiretamente, do grupo de trabalho como pessoas representativas dos distintos setores da comunidade. A participação desses elementos em programas de saúde, tais como, professores primários, alunos e líderes da comunidade, tem sido evidenciada como indispensável, tendo em vista o seu poder de melhor identificar-se com individuos e grupos da comunidade, quer na percepção e interpretação dos seus valores, quer na capacidade de estabelecer boas relações pessoais, de despertar o seu interesse e apoio, quer pela influência que exercem no impulsionamento e orientação de uma ação conjunta para a solução dos seus problemas.

A participação de professores e alunos da $5 .^{7}$ série fundamental constitui uma extensão do programa de Educação em Saúde Escolar (5), integrante do plano de saúde desenvolvido na área que tem entre os seus objetivos o de despertar, nos professores, pais e alunos, a compreensão do valor da sua participação em programas que visam o bem-estar comum.

Também, como atividade de extensão, podemos considerar a participação da curiosa, que teve atuação consciente e responsável, 
por serem as curiosas treinadas e controladas devidamente, através de um programa oficial da Secretaria de Saúde Pública do Estado, há 3 anos desenvolvido em torla a Cidlade do Salvarlor.

\section{3 -- Estabelecimento de Processos Operacionais}

Ao ser planejarla uma Campanha, não deve esta coincidir com outra, a fim de atrair a atenção da massa para um problema. Assim, sua divulgação será garantida em termos de disponibilidade dos meios de comunicação, o que é muito importante no processo de conscientização da comunidlade em relação ao problema que se pretende solucionar.

No plancjamento de uma Campanha é indispensável, antes de tudo, conhecer a comunidade, porque o conteúdo da ação deve estar baseado no problema por ela reconhecido.

Reconhecimento do problema, significa conscientização.

As reformas sociais, culturais e econômicas que se pretendem realizar só podem ser obtidas através da educação, responsável pelo processo de conscientização. Assim é que a própria Educação Sanitária deve ser considerada como parte de um processo educativo global, porque tem pouca influência, se não for apoiada por uma elucação de base.

Em campanhas dessa natureza, cujo êxito repousa na compreensão dos seus objetivos, fez-se recomendável o estabelecimento de uma dinâmica de trabalho que favoreça a comunicação como uma necessidade de presença constante do grupo de trabalho com a comunidade, a fim de reforçar os conceitos sobre a doença e suas seqüelas e o valor da vacina como medida preventiva.

\section{1 - Setorialização}

O setor é uma concentração populacional que tem como ponto de referência qualquer agência comunitária. A importância da setorialização se traduz como uma área ecológica que centraliza indivíduos com interesses comuns, cuja influência se faz sentir no grupo e vizinhança, como centro de irradiação da vacina, atendendo à necessidade de presença e facilidade de acesso.

Face às dificuldades topográficas, estabeleceu-se o zoneamento da área através do mapa, sendo em seguida realizada uma visita de reconhecimento pela equipe técnica, com a finalidade de delimitar os setores onde seriam instalados os postos fixos de vacinação. Nesta setorialização, além das vantagens que em si representa, considerou-se, como prioritários na sua delimitação, critérios outros, 
como: pontos de surgimento dos casos de poliomielite notificados à Unidade Sanitária assim como, locais de residência das curiosas, aproveitando-se da influência que exercem no seu meio-ambiente.

Com base nestes critérios foram instalados oito postos fixos, sendo quatro em escolas primárias mantidos pelo poder público e os demais, em associações de bairro e igrejas.

\section{2 - Ação Domiciliar}

A visita domiciliária tem sido praticada de forma tradicional pelo Serviço de Enfermagem de Saúde Pública, como uma técnica que of erece subsídios para um trabalho realístico e humano. Atualmente, esta forma sistemática de visitação tem sido substituída por outra dinâmica de trabalho, qual seja, a da ação grupal e de massa. Entretanto, a ação domiciliar não pode ser desprezada, impondo-se em circunstâncias especiais, tendo em vista o baixo nível das nossas comunidades. Na Campanha, a ação domiciliar foi sentida e operada com grande alcance especialmente em pontos situados na periferia da área, onde se aglomeram indivíduos marginalizados, altamente carentes de recursos humanos e materiais e, conseqüentemente, desprovidos de qualquer motivação, manifestada pelo alheamento e resistência a qualquer ação comunitária.

\section{3 - Ação Volante}

Combinada à ação domiciliar utilizou-se ação volante como técnica complementar de motivação de massa, com o objetivo de reforçar na comunidade as necessidades face ao problema, através de mensagens renovadoras. Dois postos volantes fomentaram a ação educativa da Campanha, divulgando mensagens através de megafones, cujos resultados foram bastante positivos.

\section{4 - Sistemática de Envolvimento da Comunidade}

Todo este processo foi baseado na ação inteligente e responsável do grupo de trabalho, coordenado e supervisionado, convenientemente.

Partindo da premissa de que a existência da comunidade não se determina por sua organização e maquinaria social e sim, pela medida em que as necessidades e interesses comuns dos que nela convivem, se atendem mediante planejamento e ação unificados, a tônica da Campanha foi o espírito de verdadeira reciprocidade que se fez sentir nas linhas-mestras do trabalho, quais sejam: 
- ser de interesse geral;

- ser realizado com recursos existentes;

- não alterar demasiado com os seus resultados, os hábitos e costumes da comunidade;

- servir de base para outros projetos. Assim, o grupo de trabalho organizou-se para uma ação voluntária e ajuda mútuas.

Além desta integração indispensável, aplicou-se os princípios básicos de administração, que garantem a efetividade dos trabalhos de grupos:

- determinar e classificar as funções dos integrantes do grupo e suas responsabilidades vinculadas ao programa;

- verificar se as funções específicas de cada membro estão relacionados com as dos demais participantes; isto significa integração e, só assim poderá ser considerada equipe de trabalho.

- promover a integração harmônica das atividades do grupo de trabalho com outras entidades similares existentes na comunidade.

Toda esta dinâmica serviu de base para a motivação que se pretendeu, fortalecida pelo intercâmbio de informações que envolveram os seguintes aspectos educativos:

- o que é e porque se faz a Campanha;

- o que todos devem saber sobre a poliomielite;

- qual o valor da vacina SABIN;

- como é aplicada a vacina;

- qual o grupo etário a ser vacinado;

— quando será realizada a vacina.

Todos estes aspectos foram transportados para cartazes, panfletos, spols, álbum seriado e textos para divulgação através da imprensa falada e escrita e serviços de amplificadores da comunidade.

Instrumentos informativos:

Album seriado outros líderes.

- para orientação a grupos da comunidade, professores e

Cartazes

público.

- para serem afixados em locais de maior afluência do 


\section{Panfletos}

- para professores e líderes em geral.

Volantes

- para escolares e o público em geral.

Spots

- para o público.

Faixas

- para indicação dos locais de vacinação

- para serem afixadas nas praças públicas.

\section{5 -- Avaliação}

A avaliação é um procedimento intermediário e final, uma forma de medir o êxito ou o fracasso que se vai obtendo durante o desenvolvimento e ao término de um programa.

Tratando-se da avaliação de uma Campanha na qual se testou, experimentalmente, uma sistemática de trabalho, é de toda conveniência que se analise a metodologia pela possibilidade de estabelecer comparações válidas entre os resultados atingidos e os objetivos que se pretendeu alcançar. Foi este o espírito que norteou esta avaliação, feita através da análise de todos os aspectos metodológicos da Campanha, com a apreciação dos processos utilizados, seguida da análise dos resultados oblidos, estabelecendo-se assim a relação entre os serviços prestados e os objetivos do programa.

A integração interinstitucional para assumir a competência de programas de saúde pública é um procedimento racional, realístico e humano, recomendada e enfatizada pela politica nacional de saúde. A conjugação de esforços traz vantagens de ordem técnica e econômica, haja vista a mobilização e a centralização de recursos humanos e materiais para programas que visam a objetivos comuns.

$\mathrm{Na}$ formação do grupo de trabalho, muitas vantagens foram salientadas, notadamente, o envolvimento da equipe técnica com lideres e pessoas representativas da comunidade, para um trabalho cooperativo. De fato, este relacionamento foi bastante produtivo pelo muito que representou a contribuição do técnico e da comunidarle, numa ação conjunta. Tornou-se assim um trabalho menos oneroso porque a equipe técnica atuante na área foi suficiente para manter a Campanha, desde que os seus esforços foram somados aos da comunidade sem ônus para as Instituições patrocinadoras. 
Todavia, é importante ressaltar que em trabalhos de comunidade, é indispensável a presença do elemento técnico porque, com a visão globalizada dos problemas, é capaz de orientar as adaptações e superar as demarches, pelo suporte de sua formação acadêmica. A principal função do técnico é ajudar a comunidade a utilizar as suas potencialidades para um trabalho produtivo. Na Campanha, sua ação se fez sentir na definição de problemas, na integração de atividades, na unificação de interesses e experiências e na utilização dos recursos de todos os componentes do grupo. As vantagens do trabalho de grupo refletiram-se em decisões mais eficazes, em atividades que cobriram a uma variedade de interesses e em ampla experiência para os participantes.

Foi notória a importância da coordenação da Campanha de modo a assegurar a organicidade do plano, com as vantagens de: prover o relacionamento dos grupos, conseqüentemente, o bom rendimento do trabalho, promover reuniões representativas, evitar duplicidade de funções, harmonizar técnicas e meios utilizados no aspecto educativo das' atividades programadas, utilizar racionalmente os recursos existentes e orientar as avaliações intermediárias e finais.

Quanto aos processos operacionais, além das vantagens que ofereceram isoladamente, ressaltou-se que a combinação da setorialização com a ação domiciliar e ação volante, assegurou em parte, o êxito da Campanha. A grande vantagem da combinação dos três processos, foi a de ter-se compensadas algumas deficiências surgidas no decorrer da Campanha, garantindo assim o equilíbrio das atividades.

$\mathrm{Na}$ sistemática de envolvimento da comunidade, cujos instrumentos foram extensivamente utilizados, verificou-se que foi verdadeiro o espírito de reciprocidade que se pretendeu desenvolver através das linhas mestras da Campanha.

A análise dos resultados verificou-se que da população susceptível à poliomielite foram selecionadas para vacina, 4.980 crianças da faixa etária de 2 meses a 3 anos.

O critério seletivo obedeceu a uma diretriz da Secretaria de Saúde Pública do Estado que para atender às áreas atingidas por surtos de poliomielite, teve de fazer uma distribuição racional dos seus recursos. Portanto, a seleção do grupo etário foi correlacionada à quantidade de vacina disponível.

Da população selecionada ou seja, 4.980 crianças, 4.184 $(84,2 \%)$ receberam a primeira dose da vacina e $3.088(62,0 \%)$ receberam a segunda dose. 
Convém salientar que na aplicação da primeira dose de vacina foi notória a atuação dos professores primários, alunos da $5 .^{{ }^{7}}$ série fundamental e líderes, na área de informação e participação executiva (lo trabalho. Igualmente importante foi a participação dos estudantes de Enfermagem e Medicina, na execução das várias fases da programação.

Também contou-se com dois carros volantes que, ininterruptamente, percorriam a área lançando "spots" divulgando a importância da vacina, ao tempo em que vacinava as crianças, sobretudo aquelas residentes na periferia.

Na aplicação da 2." dose da vacina, esses recursos não se fizeram sentir em toda a sua extensão. As escolas primárias reiniciavam as atividades do segundo semestre e os universitários realizavam examcs finais. Também a atuação do carro volante foi recluzida em número e horas disponíveis para o trabalho.

Todavia, relacionando os resultados alcançados na primeira e segunda doses, foram considerados, ótimo e bom, respectivamente.

A afirmativa baseada no resultado quantitativo fundamenta-se na análise de fatos que comprovam ter sido alcançado o objetivo educativo da Campanha.

A aplicação da primeira dose da vacina', nos postos fixos, apresentou um percentual em torno de $41,9 \%$, enquanto, aquela realizadla em domicílio e carros volantes apresentou, respectivamente, um percentual de $29,7 \%$ e $28,4 \%$.

Como vemos, dos três meios utilizados foram os postos fixos que apresentaram maior percentual de vacinação. $O$ fato indica $o$ deslocamento populacional da residência ao Posto, numa demonstração de consciência do problema.

Outro ponto que merece ser focalizado é aquele relacionado à vigilância epidemiológica .

Foi verificado que o percentual de crianças vacinadas foi suficiente para quebrar a cadeia de transmissão da doença na área. Assim é que, embora duas crianças fossem acometidas de poliomielite, dez dias após o término da Campanha, nenhum outro caso foi registrado até a presente data. Isto indica que a vacinação deu a proteção desejada à população susceptível.

As considerações anteriores demonstram o esforço da Universidade Federal da Bahia, através das suas Escolas de Enfermagem e Medicina, para que o ensino profissionalizante se desenvolva num amplo contexto sócio-econômico e cultural. 
A execução de atividades realizadas de maneira ótima, com limitados recursos para a tarefa a executar, muito poderá contribuir para desenvolver a criatividade do estudante, no sentido de produzir serviços com recursos limitados.

\section{III - CONCLUSÃO}

A apreciação dos aspectos metodológicos da Campanha ao lado da análise dos resultados obtidos, chegou-se à conclusão de que os processos utilizados na sua dinâmica, favoreceram o alcance dos objetivos traçados.

Parece-nos oportuno ressaltar que a Campanha revelou-se, de fato, um método de motivação de massa, haja vista o seu poder de penetração na Comunidade através de um processo educativo contínuo que constituiu a tônica do trabalho em todas as suas etapas.

Considerando a educação em saúde, um aspecto da educação global, é de toda conveniência o desenvolvimento da educação de base para o aceleramento de programas de Saúde Pública. Assim é que, a educação da população do Nordeste de Amaralina tem sido fomentada através do Plano de Desenvolvimento Comunitário, já referido neste trabalho. Este plano integra programas de grande alcance, entre eles, o de Educação em Saúde Escolar e o de Treinamento e Controle de Curiosas. Por isto, a participação de alunos da $5 .^{q}$ série fundamental assim como, de curiosas, no grupo de trabalho da Campanha, foi considerada como atividade de extensão desses programas, o que foi comprovadamente positivo, uma vez que esses elementos já tinham a consciência de saúde, através dos conhecimentos adquiridos.

O programa de Educação em Saúde Escolar tem merecido destaque especial na seleção de prioridades da ação governamental na Bahia, a ponto de ser oficializado em março deste ano, com um raio de ação que deverá atingir toda a Cidade de Salvador.

A educação para escolares pode ser definida como um processo de aprendizagem capaz de influir na mudança de comportamento e atitudes da criança em relação à sua própria saúde e da comunidade.

Cabe pois ao professor, cujo treinamento constitui uma etapa do programa de Saúde Escolar, um papel múltiplo porém, bem definido junto aos alunos e à comunidade, uma vez que a Escola se constitui uma poderosa agência comunitária.

A participação entusiasta e efetiva de estudantes de Enfermagem e Medicina na Campanha, constituiu a medida do seu aprendizado, através de uma experiência rica em todos os aspectos. 
Ao finalizar este trabalho, esperamos ter contribuído de alguma maneira com subsílios para o planejamento, execução e avaliação de programas dessa natureza.

\section{REFERENCIAS BIBLIOGRÁFICAS}

1 - BOLETIM de la Oficina Sanitaria Pan-Americana. 66(5) : 375-450 , mayo, 1969.

2 - NEVROTROPIC Viral Diseases Anual Poliomyelites, Summary, 1967, Nat. Comum. Dis Center, June 30, 1968.

3 -- PUGLIESI, C., et ali: Plano de Desenvolvimento Comunitário do Nordeste de Amaralina I - Inquérito de Saúde Anais do Seminário. A saúde da Comunidade. A estatística como instrumento de trabalho. Associação Brasileira. Escolas Médicas Manguinhos, GB. 19 a 22 de agosto, 1969 .

4 - SILVA, I.C., et ali: Saúde Escolar. Um estudo dos problemas de saúde escolar em uma comunidade urbana de Salvador - Nordeste de Amaralina - Salvador - U.F.BA. Faculdade de Nedicina e Escola de Enfermagem, 1970.

5 -... Silva, I.C., Edlucação em Saúde Escolar: Análise de uma experiencia. Salvador, Escola de Enfermagem, Universidade Federal da Bahia, 1971. 